\title{
A RETROSPECTIVE AUDIT OF 381 CASES OF HYPOSPADIAS CORRECTION IN A REGIONAL PAEDIATRIC SURGERY CENTRE
}

\author{
I. Raymond ${ }^{1}$, N. Vasdev ${ }^{1,2}$, A. Thorpe ${ }^{1}$, M. De La Hunt ${ }^{2}$, I. Willetts ${ }^{2}$ \\ ${ }^{I}$ Freeman Hospital, ${ }^{2}$ Royal Victoria Infirmary, Newcastle upon Tyne, UK
}

Background and aim: To retrospectively review the management of hypospadias in a single regional centre, assess the spectrum of cases treated, operative techniques used and determine the nature of complications.

Methods: 381 patients underwent hypospadias surgery from January 1994 to January 2008. Information was collected retrospectively and this included hypospadias type, presence of chordee, surgical technique, complications and outcome of follow up.

Results: The mean age at presentation and surgery was 10.3 months(Range $0.02-156)$ and 22.3 months (Range 4.2 - 162) respectively. The types of hypospadias treated were anterior $\{279(73 \%)]$, middle $[\mathrm{n}=79(21 \%)$ and posterior $[\mathrm{n}=23(6 \%)]$. Additional conditions included chordee in $106\{28 \%)$, un-descended testis in $10(2.6 \%)$ and intersex in $1(2.6 \%)$ patients.

At a mean follow up of 31.4 months(Range $1-179$ ), the incidence of fistulas, urethral strictures and meatal stenosis were $11.3 \%(43), 12.8 \%(49)$, and $3.7 \%$ (14\%) respectively.

\begin{tabular}{|c|c|c|c|}
\hline $\begin{array}{c}\text { Operative procedures } \\
{[\%\{n)]}\end{array}$ & $\begin{array}{c}\text { Anterior hypospadias } \\
{[\%\{n)]}\end{array}$ & $\begin{array}{c}\text { Middle hypospadias } \\
{[\%\{n)]}\end{array}$ & $\begin{array}{c}\text { Posterior hypospadias } \\
{[\%\{\text { n })]}\end{array}$ \\
\hline GRAP [81.4\% (243)] & $68.5 \%(243)$ & $12.9 \%(46)$ & 0 \\
\hline $\begin{array}{l}\text { Durham Smith [5.92\% } \\
(21)]\end{array}$ & 0 & $1.41 \%(5)$ & $4.51 \%(16)$ \\
\hline Snodgrass [11\% (39)] & $1.97 \%(7)$ & $7.89 \%(28)$ & $1.13 \%(4)$ \\
\hline MAGPI [0.28\% (1)] & $0.28 \%(1)$ & 0 & 0 \\
\hline $\begin{array}{l}\text { Free preputial graft } \\
{[0.28 \%(1)]}\end{array}$ & 0 & 0 & $0.28 \%(1)$ \\
\hline BRACKA [0.28\% (1)] & 0 & 0 & $0.28 \%(1)$ \\
\hline $\begin{array}{l}\text { Byar's flap repair }[0.56 \% \\
\text { (2) }\end{array}$ & $0.28 \%(1)$ & $0.28 \%(1)$ & 0 \\
\hline
\end{tabular}

[Table 1 - Type of surgical hypospadias repair]

Conclusion: A thorough assessment of the defect and precise application of specific hypospadias surgery allows for successful correction of even complex hypospadias with a minimal complication rate. 